\title{
Economic Effects of Inward Foreign Direct Investment in Myanmar
}

\author{
Thet Mon Soe ${ }^{1}$
}

\begin{abstract}
This paper aims to examine the effects of inward foreign direct investment (FDI) on economic growth and domestic investment at the regional-level and sectoral-levels of Myanmar economy, by applying a panel vector-autoregressive model framework. The major research questions are twofold: whether inward FDI causes economic growth or economic growth attracts inward FDI, and whether inward FDI crowds in or crowds out domestic investment. The main findings are summarized as follows. In the regional level analysis, there is a difference in the FDI-economic growth relationship between the FDI-intensive region and the FDI-less-intensive one. In the FDI-intensive region, the bidirectional FDI-economic growth relationship is found, supporting the both hypotheses of FDI-driven growth and growth-driven FDI, while the FDI-driven growth effect is larger than the growth-driven FDI one. In the FDI-less-intensive region, on the other hand, FDI deteriorates economic growth whereas economic growth still induces FDI. The difference in the FDI-economic growth relationship between the regions might come from the gap in agglomeration effects. In the sectoral level analysis, the crowd-in effect of FDI on domestic investment is found in the non-oil and gas sectors, since the FDI in the oil and gas sector has less linkages to domestic investment.
\end{abstract}

JEL classification numbers: F21; O53

Keywords: Inward foreign direct investment, Myanmar, Economic growth, Domestic investment, Panel vector autoregressive model

\section{Introduction}

With the rise of globalization, the Association of South East Asian Nations (ASEAN) has liberalized their policies on foreign direct investment (FDI) in favor of attracting inward FDI, which is the principal factor for accelerating economic development. ASEAN has gradually become one of the leading destinations for FDI with an increasing global share of inward FDI stock from 2.52 percent in 1989 to 7.37 percent in 2019. At the same time, the inward FDI stock share to GDP in ASEAN also rose significantly from 14.10 percent to 84.70 percent $^{2}$.

Myanmar, one of ASEAN members, has been now actively re-engaged with global value chains after the establishment of a civilian government led by President U Thein Sein in March 2011. After 2011, the western countries gradually lifted political and economic sanctions. Thus Myanmar has a great opportunity to re-join the global economy. In order to fully reap the benefits, the inward FDI could be a key driving force for industrialization in Myanmar. In this respect, Myanmar government has launched a

\footnotetext{
${ }^{1}$ Saitama University, Japan

2 The figure is based on UNCTAD Stat: https://unctadstat.unctad.org/EN/
} 
wide-ranged reformations to enhance its investment climates, in particular, by enacting Myanmar Investment Law (MIL) in October 2016. The MIL is the consolidation of Myanmar Citizen Investment law (2013) and Myanmar Foreign Investment Law (2012), designed to facilitate and promote domestic and foreign investments.

In an effort to attract inward FDI, it is critically important to know how inward FDI interacts with economic growth and which sector is the most effective and efficient sector to absorb inward FDI. To deal with these issues, researches have been discussing and analyzing the effect of inward FDI theoretically and empirically, though there have been no clear consensus on the results.

Theoretically, in the context of FDI-driven growth hypothesis, both the neoclassical growth model (Solow, 1956) and the endogenous growth model (Romer, 1990) argues that the accumulation of capital stock and technological progress are the principal determinants of economic growth, but they differ in the treatment of technology. The neoclassical model treats technological progress as an exogenous variable, and assumes that FDI merely increases the investment rate, resulting in a transitional growth in per capita income. In the endogenous growth model, however, technological progress is considered to be endogenous, and FDI is assumed to have a permanent growth impact via its technological transfer and spillover effects.

From the empirical perspective, a number of empirical studies has examined the economic impacts of inward FDI, but there have still been controversial issues in the following aspects. Some studies identified the positive effect of inward FDI on economic growth, whereas the others found the opposite causality between inwards FDI and economic growth: the FDI could be attracted by growing economies and markets, which is referred to as the "market-size hypothesis" or the "growth-driven FDI hypothesis" proposed by e.g. Caves (1996) and Zhang (1999, 2001). Another dispute is whether inward FDI crowded-in or crowded-out domestic investment.

This study set out to investigate the effects of inward FDI on economic growth and domestic investment at the regional and sectoral levels of Myanmar economy, by applying the toolkit of a panel vector-autoregressive (PVAR) model: granger causality test, impulse response function analysis and variance decomposition check. The reason for using the PVAR model in this study is that there is the endogeneity problem among the variables of FDI, economic growth and domestic investment.

The specific research questions in this study are twofold: whether the inward FDI causes economic growth or economic growth attracts the FDI, and whether the inward FDI crowds in or crowds out domestic investment. The reginal analysis focuses on the causality between inward FDI and economic growth. The regions and states in Myanmar are divided according to the FDI-value intensity (the FDI-intensive region and the FDI-less-intensive region) with an aim to analyze the differences in the FDI - economic growth relationship. The hypothesis behind the reginal division is that the FDI intensity is supposed to create agglomeration effects on economies through technological spillovers and industrial linkages. The sectoral analysis is for examining the crowd-in or -out effects of inward FDI on domestic investment. Since the investment in the oil and gas sector is dominated only by FDI, the sectors without the oil and gas are examined as well as the sectors including the oil and gas.

The rest of the paper is structured as follows. Section 2 presents a review of literature with a focus on the empirical studies on FDI-growth relationship in emerging-market and developing economies, and clarifies the contribution of this study. Section 3 conducts an empirical estimation, describing the methodology, data and estimation outcomes with its interpretations. The last section summarizes and concludes with policy implications. 


\section{Literature Review and Contribution}

This section reviews the literature related to FDI-growth relationship in emerging-market and developing economies including Myanmar. The studies could be classified by the examined samples depending on the national, regional and sectoral levels.

Regarding the national-level analyses, there are some empirical studies targeting multi-countries with mixed results. Oladipo (2012), sampling 16 developing countries, identified the causality from FDI to economic growth in majority of sample countries and the reverse causality from growth to FDI in half of samples. Chowdhury and Mavrotas (2006) found the unilateral causality from GDP to FDI in Chile, and the bilateral causality between them in Malaysia and Thailand. These studies imply the need of different kinds of policies depending on the modality of the causality. On the other hand, Zhang (2001), sampling 11 economies, showed that the extent to which FDI is growth-enhancing depended on host-country-specific characteristics such as trade regime, human capitals, FDI policies and macroeconomic stability. As for the studies focusing on a single country e.g. China, Shan (2002) found the two-way causality between FDI and output growth though the causality from growth to FDI was more significant. On the contrary, Zhao and Du (2007) confirmed only the impact of economic growth on FDI influx, which supported the market-size hypothesis.

For the regional-level analyses, Changyan (2007), using the panel data of provinces in China, found that FDI produced positive effects on China's economy via its crowding-in domestic investments, not through its direct channel on economic growth. Taguchi and Pham (2019), sampling the provincial data in Vietnam, showed the contrasts on FDI effects between the FDI-intensive region and the FDI-less intensive one: FDI caused growth and crowded in domestic investment in the FDI-intensive region, whereas growth caused FDI and FDI crowded out domestic investment in the FDI-less-intensive one.

Concerning the sectoral-level analyses, Aykut and Sayek (2007), using cross-country data, revealed that FDI had a positive effect on economic growth as the share of the manufacturing sector in FDI flows increase, while having a negative effect as the share of primary and services sector in FDI increases. Shah et al. (2020), examining the case of Pakistan, found that FDI in manufacturing and services sectors, but not in primary sector, crowded in domestic investment.

The FDI-growth studies focusing on Myanmar that this study targets are quite limited even in the national-level analyses. It is probably because it is only after the sanctions imposed by western countries was lifted during the 2010s that the FDI influx has been activated in Myanmar. Taguchi and Ni Lar (2015) could not identify the causality from FDI to GDP with the sample for 1984-2012 in Myanmar, and picked up the following reasons: too small scale of FDI, much dependence on oil and gas sectors in FDI and the lack in time-series sample data. Bissinger (2012) also pointed out that the FDI concentrating on extractive sectors has retarded the economic growth of Myanmar. The recent study, Thunt and Jung (2018), sampling the period for 1970-2016, found that the FDI has a positive effect on GDP per capita growth in the long-run as well as in the short-run by using a Vector Error Correction Model.

To sum up, there has been no clear consensus in the empirical literature on the causality between FDI and economic growth. and the FDI effects on GDP and domestic investment. As far as Myanmar economy is concerned, there has been few evidence on the FDI- growth relationship. In this context, the contributions of this study to the existing literature could be highlighted as follows.

First, this study contributes to enriching the evidence on the FDI-growth relationship in Myanmar under the lack in its empirical studies. The evidence of this study could be significant enough to add to the literature, since it would be the first time to examine its relationship using regional and sectoral data in Myanmar. The recent availability of the time-series data for 2012-2018 makes it possible to analyze the interaction among FDI, GDP and domestic investment at the regional and sectoral levels. 
Second, this study uses not a single-equation regression but a PVAR model to avoid the endogeneity problem among targeted variables. The PVAR estimation lets the data determine the causality between targeted variables, and makes it possible to trace out the dynamic responses of variables to exogenous shocks overtime.

\section{Empirical Results}

This section conducts an empirical analysis using a PVAR model for examining the relationship among FDI, growth and domestic investment. The section describes the methodology, data and estimation outcomes with its interpretations.

\subsection{Methodology: PVAR Estimation}

In the estimation, monetary and external sectors are assumed to be an equilibrium at the national level so that interest rate and exchange rate can be given. This assumption would be justified since this study's analysis targets regions and sectors in Myanmar. The study thus focuses only on the real aspect of the economy, ignoring the financial variables.

The estimation uses three macroeconomic variables for two research questions: inward FDI and gross regional products (GRP) in each region and state, for examining the causality between FDI and economic growth; and inward FDI and domestic investment (DIV) in each sector, for the analysis of the crowding-in or -out effects of inward FDI on domestic investment.

Since all the variables above are in the context of endogenous property and the direction of the causality is controversial, using a single-equation regression approach would lead to the existence of biased and inconsistent estimators. To deal with these issues, a PVAR model is the most coherent and credible approach for the following two reasons: a PVAR model is the data-based system such that the data determine the direction of the causality (Sims, 1980); and each variable in the model is explained by its own lags and lagged values of other variables (Gujarati, 2004). Regarding the estimation technique of the PVAR, this study follows Abrigo and Love (2016).

As a toolkit of the PVAR model estimation, this study employs Granger causality test (GC), impulse response function (IRF) and forecast error variance decomposition (FEVD) on the bilateral combinations between FDI and GRP and between FDI and DIV. The GC identifies the direction of the causality between a pair of variables; the IRF traces out the impact of a one-unit shock to one variable on the other variable: the FEVD separates the variation in one variable into the component shock so that it can provide information about the relative importance of each random innovation in affecting the variable. Regarding the lag interval, the study takes one-year lag, following the Schwarz Information Criterion with the maximum lags being equal to two year lags under the limited number of time-series data. Then the first PVAR model estimation together with GC, IRF and FEVD on the combination between FDI and GRP is conducted by using reginal data in Myanmar, in terms of the nation-wide model and the regional model divided into two groups of the FDI-intensive region and the FDI-less-intensive region. The second PVAR model on the combination between FDI and DIV is conducted by using sectoral data in Myanmar, in terms of the total-sector model and the model without the oil and gas sector.

\subsection{Data Description}

This subsection describes the data sources and the sample data used for the estimation. The first PVAR model requires two variables' datasets: FDI and GRP. The data of FDI is obtained from Directorate of Investment and Company Administration (DICA) in Myanmar as a permitted-value base, and that of GRP is from the annual report of Planning Department of Myanmar. The FDI values on US dollar base 
are converted into those on local-currency (Kyat) base by the exchange rate retrieved by International Financial Statistics (IFS) of International Monetary Fund (IMF). Since the FDI significant data is available only after 2012, a national level analysis faces the lack in time-series sample. Hence comes the necessity to disaggregate the data into regional or sectoral levels. Then the first PVAR estimation chooses the regional disaggregation for FDI and GRP, because sectoral classifications in both dataset mismatch each other ${ }^{3}$. Table 1 lists up 15 regions and states as the sample for the estimation. The time series sample of each region and state for FDI and GRP are available for 2012-2017. Thus for the PVAR estimation of the nation-wide model, the study constructs a panel data with 15 regions and states for 2012-2017.

Then this study classifies the regions and states into three categories: the FDI-intensive region, the FDI-less-intensive region and the oil-and-gas FDI-intensive region. The reason why the oil-and-gas FDI is treated separately is that the investment in that sector, different from those in other sectors, is dominated by FDI with the less linkage to domestic investment. Tanintharyi Region, Rakhine State and Ayeyarwaddy Region are classified into the oil-and-gas FDI-intensive region, since their oil-and-gas productions accounts for 96.0 percent out of its nation-wide production, and their FDIs are dominated by the oil-and gas sector. Excluding the oil-and-gas FDI-intensive region, the remaining regions and states are further divided into two groups according to the FDI intensity measured by their FDI values for the average for 2012-2017. To be specific, the sample regions and states are arranged in the sequence of the FDI values from the top to the bottom. Then the first half group from the top (Yangon Region) to the 6th (Sagaing Region) is called "the FDI-intensive region" and the latter half group from the 7th (Shan State) to the bottom (Chin State) is called "the FDI- less-intensive region". For the PVAR estimations for each region, the study constructs a panel data with 6 regions and states provinces for 2012-2017, respectively.

The second PVAR model needs two variables' datasets: FDI and DIV. Both data are taken from the DICA as a permitted-value base. The FDI values on US dollar base are converted into those on Kyat base by the exchange rate retrieved by the IMF-IFS. The second PVAR estimation adopts the sectoral disaggregation for FDI and GRP for the following reasons. First, the sectoral-level analysis seems to be suitable for the analysis of crowding-in or -out effects of FDI on domestic investment, since the technological spillovers in intra-industries could directly be addressed in that analysis. Second, the sectoral classifications on both dataset is perfectly consistent, since they come from the same DICA data source. The sectors could be divided into 11, and the time series sample of each sector are available for 2012-2018. Thus for the PVAR estimation of the total-sector model, the study constructs a panel data with 11 sectors for 2012-2018. In addition, the study also estimated the model without the oil and gas sector, since the investment in the oil and gas sector is dominated by FDI with the less linkage to domestic investment.

\subsection{Data Property}

Before conducting the PVAR analysis, the study examines the stationary property of the data through a panel unit root test, on the regional panel of FDI and GRP for the first PVAR model estimation, and on the sectoral panel of FDI and DIV for the second model estimation. The unit root test is conducted on the null hypothesis that a level of the individual data has a unit root. The pre-tests for unit roots are critical in determining the appropriate transformations that render the data stationarity by reducing the estimation uncertainty and the degree of small-sample bias of impulse response estimates (Gospodinov et al., 2013).

With respect to a panel unit root test, the study employs the Levin-Lin-Chu unit root test (proposed by Levin et al., 2002), which assumes that the parameters of the series lagged are common across cross

\footnotetext{
${ }^{3}$ For instance, the GRP data has no classification of "Hotel and Tourism", Real Estate Development" and
} "Industrial Estate" that the FDI data has in its sectoral classification. 
sections. The test equation is specified by containing "individual intercept" and "individual intercept and trend" with the lag length being automatic selection.

The test results for each variable used for the first and second PVAR model estimations are reported in Table 2. The test rejected a unit root at the conventional level of significance in all the data except the GRP with the specification of individual intercept, thereby their data showing stationary property. Their level data are thus justified to be used for the subsequent estimation.

\subsection{Estimation Outcomes}

The estimation outcomes are reported by two levels of the PVAR model analyses in the following subsections: the regional-level analysis on the relationship between FDI and GRP; and the sectoral-level analysis on the relationship between FDI and DIV.

\subsubsection{Regional Analysis on Relationship between FDI and GRP}

Table 3 and Figure 1 report the estimated PVAR model with Granger causality test (GC), impulse response function (IRF) and forecast error variance decomposition (FEVD) on the regional-level analysis between FDI and GRP. The outcomes are shown for the nation-wide model, and the regional model divided into two groups of the FDI-intensive region and the FDI-less-intensive region.

Regarding the GC test, the bidirectional causalities between FDI and GRP are identified at the conventional level of significance (99 percent) in the nation-wide model. When the region is disaggregated into the FDI-intensive region and the FDI-less-intensive region, the results show a contrast in the causality from FDI to GRP between two regions: the "positive" causality in the FDI-intensive region and the "negative" causality in the FDI-less-intensive region, while the positive causality from GRP to FDI is commonly found in the both regions.

In the IRF analysis, the outcomes are in line with those of the GC test. In the nation-wide model, GRP responds positively to the one-unit shock of FDI continuously from the beginning with 95 percent error band, and vice versa. In the regionally disaggregated level, there is also a contrast in the GRP response to FDI shock: the "positive" response in the FDI-intensive region and the "negative" one in the FDI-less-intensive region, while the positive response of FDI to GRP shock is commonly found in the both regions. Through the results of the GC test and IRF analysis, it could be speculated that the nation-wide estimation is heavily affected by the estimation targeting the FDI-intensive region.

As for the FEVD results, focusing on the regional disaggregation, FDI's contributions to GRP variance after eight quarters are 70.6 percent in the FDI-intensive region and 42.9 percent in the FDI-less-intensive region, whereas GRP's contributions to FDI variance after eight quarters are only under one percent in the both regions. This outcomes imply that the impacts of FDI on GRP are larger than those of GRP on FDI.

\subsubsection{Sectoral Analysis on Relationship between FDI and DIV}

Table 4 and Figure 2 report the estimation results on PVAR model, the GC test, the IRF analysis and the FEVD check on the sectoral regional-level analysis between FDI and DIV. The outcomes are shown for the total-sector model and the model without the oil and gas sector.

Regarding the GC test, it is only in the model excluding the oil and gas sector that the causality is identified from FDI to DIV at the conventional level of significance (95 percent). The IRF consistently shows that DIV responds positively to FDI with 95 percent error band in the model excluding the oil and gas sector. As for the FEVD in the model excluding the oil and gas sector, FDI's contributions to DIV variance after eight quarters are 19.8 percent, while DIV's contributions to FDI variance are only 4.3 percent. 


\subsection{Interpretations of Estimation Outcomes}

This subsection interprets the estimation outcomes above by each model at regional and sectoral level analyses, from the perspectives of the causality between FDI and economic growth and the crowding-in or crowding-out effect of FDI on domestic investment.

In the regional level analysis, there is a difference in the FDI-economic growth relationship between the FDI-intensive region and the FDI-less-intensive one. In the FDI-intensive region, the bidirectional FDI-economic growth relationship is found, and it means that the both hypotheses, the FDI-driven growth hypothesis and the growth-driven FDI hypothesis (market-size hypothesis), are valid in that region. From the FEVD analysis, the FDI-driven growth effect is considered to be larger than the growth-driven FDI one, and its effect, which is found to be not temporary but long-lasting, seems to follow the endogenous growth theory rather than the neoclassical growth one. In the FDI-less-intensive region, on the other hand, FDI deteriorates economic growth while economic growth induces FDI as in the FDI-intensive region.

The difference in the FDI-economic growth relationship between the regions might come from the gap in agglomeration effects. For instance, Yangon, the top FDI-recipient region of Myanmar, has developed the special economic zones (SEZs) to intensively invite the foreign investors. The SEZs are the convenient avenues to create a cluster and network between foreign companies and local ones, so that the technological spillovers and inter- and intra- industrial linkages could be facilitated in effective ways. In the FDI-less-intensive regions (from Shan State to Chin State in Table 1), on the other hand, there have been no active SEZs to link foreign investors' activities with local companies. Although FDI comes into these regions with the limited resources like skill labors and absorptive capacities, the foreign investors might even result in crowding out local resources and local firm's activities.

In the sectoral level analysis, it is reasonable that the crowd-in effect of FDI on domestic investment is only found in the non-oil and gas sectors, since the FDI in the oil and gas sector has less linkages to domestic investment.

The contributions of this study's results in comparison with previous findings in the literature shown in Section 2 could be highlighted as follows. First, in the regional level analysis, this study could reveal a clear contract in the validity of the FDI-driven growth hypothesis in Myanmar: the hypothesis is valid in the FDI-intensive region but not in the FDI-less-intensive region. This contrast is perfectly consistent with the one in the Vietnamese regional analysis conducted by Taguchi and Pham (2019). Thus this study could enrich the evidence on the regional gap in the FDI-driven growth effect in the ASEAN latecomers such as Myanmar and Vietnam. Second, in the sectoral level analysis, this study could reconfirm the crowd-in effect of FDI on domestic investment only in the "non-oil and gas" sectors in Myanmar. This outcome is in line with the evidence in Pakistan provided by Shah et al. (2020), and is also consistent with the arguments on Myanmar's case presented by Bissinger (2012) and Taguchi and Ni Lar (2015). Thus this study could endorse the previous studies' arguments through empirical tests in Myanmar.

\section{Concluding Remarks}

This paper examined the effects of inward FDI on economic growth and domestic investment at the regional-level and sectoral-levels of Myanmar economy, by applying the PVAR model framework. The major research questions are twofold: whether inward FDI causes economic growth or economic growth attracts inward FDI, and whether inward FDI crowds in or crowds out domestic investment. The regional-level analysis focuses on the causality between FDI and economic growth, and the regions are disaggregated according to the FDI-value intensity (the FDI-intensive region and the FDI-less-intensive region) with an aim to analyze the differences in the FDI - economic growth relationship. The sectoral-level analysis is for examining the crowd-in or -out effects of FDI on domestic investment for the 
total sectors and the non- oil and gas sectors.

The main findings are summarized as follows. In the regional level analysis, there is a difference in the FDI-economic growth relationship between the FDI-intensive region and the FDI-less-intensive one. In the FDI-intensive region, the bidirectional FDI-economic growth relationship is found, supporting the both hypotheses of FDI-driven growth and growth-driven FDI, while the FDI-driven growth effect is larger than the growth-driven FDI one. In the FDI-less-intensive region, on the other hand, FDI deteriorates economic growth whereas economic growth still induces FDI. The difference in the FDI-economic growth relationship between the regions might come from the gap in agglomeration effects. In the sectoral level analysis, the crowd-in effect of FDI on domestic investment is found in the non-oil and gas sectors, since the FDI in the oil and gas sector has less linkages to domestic investment.

Based on the above-mentioned findings, the following policy implication for inward FDI could be suggested in Myanmar economy. Since the significance of inward FDI in economic growth depends on its agglomeration effects, the policy should be designed to facilitate the technological spillovers and interand intra- industrial linkages between create foreign companies and local ones. In the FDI-less-intensive regions, establishing the SEZs with effective infrastructure is one of the options for accepting inward FDI. Another option might be to focus on domestic-firm-driven development, not relying on FDI, in such fields as agro-business and tourism, since it seems to be difficult for all the regions to set up the SEZs specific for inward FDI.

\section{References}

Abrigo, M.R.M. and Love, I. 2016. Estimation of Panel Vector Autoregression in Stata. The Stata Journal, 16: 778-804.

Aykut, D. and Sayek, S. 2007. The Role of the Sectoral Composition of Foreign Direct Investment on Growth, in Santangelo, G.D. and Piscitello, L. (eds), Do Multinationals Feed Local Development and Growth? International Business and Management, 22: 35-59, Amsterdam: Elsevier.

Bissinger, J. 2012. Foreign Investment in Myanmar: A Resource Boom but a Development Bust? Contemporary Southeast Asia, 34(1): 23-52.

Caves, R. 1996. Multinational Enterprises and Economic Analysis, $2^{\text {nd }}$ ed. Cambridge: Cambridge University Press.

Changyuan, L. 2007. FDI, Domestic Capital and Economic Growth: Evidence from Panel Data at China's Provincial Level. Frontiers of Economics in China, 2: 92-113.

Chowdhury, A. and Mavrotas, G. 2006. FDI and Growth: What Causes What? The World Economy, 29(1): 9-19.

Gospodinov, N., Herrera, A.M. and Pesavento, E. 2013. Unit Roots, Cointegration, and Pretesting in Var Models. Advances in Econometrics, 32: 81-115.

Gujarati, D.N. 2004. Basic Econometrics, $4^{\text {th }}$ ed. New York: McGraw-Hill Companies.

Levin, A., Lin, C.F. and Chu, C.S.J. 2002. Unit Root Tests in Panel Data: Asymptotic and Finite-Sample Properties. Journal of Econometrics, 108(1): 1-24.

Oladipo, O.S. 2012. Does Foreign Direct Investment Cause Long Run Economic Growth? Evidence from the Latin American and the Caribbean Countries. International Economics and Economic Policy, 10(4): 569-582.

Romer, P.M. 1990. Endogenous Technological Change. The Journal of Political Economy, 98: S71-S102.

Shah, S.H.S., Hasnat, H. and Cotterell, S. 2020. Sectoral FDI Inflows and Domestic Investments in Pakistan. Journal of Policy Modelling, 42: 96-111.

Shan, J. 2002. A Var Approach to the Economics of FDI in China. Applied Economics, 34(7): 885-893. 
Sims, C.A. 1980. Macroeconomic and Reality. Econometrica, 48(1): 1-48.

Solow, R.M. 1956. A contribution to the Theory of Economic Growth. The Quarterly Journal of Economics, 70: 65-94.

Taguchi, H. and Ni Lar. 2015. FDI, Industrial Upgrading and Economic Corridor in Myanmar. Chapter VI, Progress Report on the Potentials on the Indochina Economic Zone, Economic and Social Research Institute, Cabinet Office: 99-133.

Taguchi, H. and Pham, H.K. 2019. Economic Effects of Inward Foreign Direct Investment: The Case of Vietnamese Provinces. Journal of Advanced Studies in Finance, 10(1): 9-21.

Thunt, H.O. and Jung, S.H. 2018. A Study on the Interrelationships among Trade, Foreign Direct Investment, Human Capital, Financial Development and Economic Growth in Myanmar, Journal of International Trade \& Commerce, 14(4): 63-84.

Zhao, C. and Du, J. 2007. Causality between FDI and Economic Growth in China. Chinese Economy, 40 (6): 68-82.

Zhang, K.H. 1999. How Does FDI Interact with Economic Growth in a Large Developing Country? The Case of China. Economic System, 21(4): 291-303.

Zhang, K.H. 2001. Does Foreign Direct Investment Promote Economic Growth? Evidence from Asia and Latin America. Contemporary Economic Policy, 19(2): 175-85. 
Table 1: Classification of Regions and States by FDI in Myanmar

\begin{tabular}{|c|c|c|}
\hline Regions \& States & $\begin{array}{c}\text { FDI values } \\
\text { average for 2012-2017 } \\
\text { million kyat }\end{array}$ & FDI intensity \\
\hline Yangon Region & $3,704,365$ & \multirow{6}{*}{ insentive } \\
\hline Mandalay Region & 632,260 & \\
\hline Mon State & 282,911 & \\
\hline Bago Region & 269,552 & \\
\hline Magway Region & 108,585 & \\
\hline Sagaing Region & 84,980 & \\
\hline Shan State & 64,130 & \multirow{6}{*}{ less intensive } \\
\hline Kachin State & 54,853 & \\
\hline Naypyitaw & 9,600 & \\
\hline Kayin State & 8,305 & \\
\hline Kayah State & 328 & \\
\hline Chin State & 0 & \\
\hline Tanintharyi Region & 830,224 & \multirow{3}{*}{ Oil \& Gas } \\
\hline Rakhine State & 493,688 & \\
\hline Ayeyarwaddy Region & 63,296 & \\
\hline
\end{tabular}

Source: Directorate of Investment and Company Administration (DICA) in Myanmar

Table 2: Unit Root Test

\begin{tabular}{ccc}
\hline \hline & \multicolumn{2}{c}{ Unit Root Test (Levin, Lin \& Chu Test) } \\
\cline { 2 - 3 } & Intercept & Intercept \& Trend \\
\hline \hline [FDI \& GRP: regioanl panel] & & $-15.232 * * *$ \\
FDI & $-6.231 * * *$ & $-2.978 * * *$ \\
GRP & 12.827 & $-6.342 * * *$ \\
\hline [FDI \& DIV: sectral panel] & & $-15.312 * * *$ \\
FDI & $-4.131 * * *$ & $-12.984 * * *$ \\
DIV &
\end{tabular}

Note: $* * *, * *, *$ denote the rejection of null hypothesis at the $99 \%, 95 \%$ and $90 \%$ level of significance. Source: Author's estimation 
Table 3: Regional Analysis on Relationship between FDI and GRP

Table 3.1: Estimated PVAR Model

[Nationwide]

\begin{tabular}{ccc}
\hline \hline FDI \& GRP & FDI & GRP \\
\hline \multirow{2}{*}{ FDI-1 } & $0.636 * * *$ & $0.106 * * *$ \\
& {$[6.536]$} & {$[3.282]$} \\
\hline \multirow{2}{*}{ GRP-1 } & $0.072 * * *$ & $1.112 * * *$ \\
& {$[3.643]$} & {$[168.747]$} \\
\hline adj. R^2 & 0.631 & 0.996 \\
\hline \hline [FDI-intensive Region] & FDI & GRP \\
\hline \hline FDI \& GRP & $0.804 * * *$ & $0.156 * * *$ \\
\hline \multirow{2}{*}{ FDI-1 } & {$[6.490]$} & {$[5.874]$} \\
\hline \multirow{2}{*}{ GRP-1 } & $0.058 * *$ & $1.112 * * *$ \\
& {$[2.297]$} & {$[201.798]$} \\
\hline adj. R^2 & 0.806 & 0.998 \\
\hline \hline [FDI-less-intensive Region] & & GRP \\
\hline \hline FDI \& GRP & FDI & $-1.060 * * *$ \\
\hline \multirow{2}{*}{ FDI-1 } & -0.472 & {$[-2.770]$} \\
\hline \multirow{2}{*}{ GRP-1 } & {$[-1.281]$} & $1.109 * * *$ \\
\hline adj. R^2 & $0.022 * * *$ & {$[133.677]$} \\
\hline \hline & {$[2.757]$} & 0.997 \\
\hline & 0.096 & \\
\hline
\end{tabular}

Note: $* * *, * *, *$ denote the rejection of null hypothesis at the $99 \%, 95 \%$ and $90 \%$ level of significance. The t-statistic is in parentheses [ ].

Sources: Author's estimation

Table 3.2: Granger Causality Test

[Nationwide]

\begin{tabular}{ccc}
\hline \hline Null Hypothesis & df & Chi-sq \\
\hline FDI does not Granger Cause GRP & 1 & $10.774 * * *$ \\
GRP does not Granger Cause FDI & 1 & $13.275^{* * *}$ \\
\hline \hline [FDI-intensive Region] & df & Chi-sq \\
\hline Null Hypothesis & 1 & $34.507 * * *$ \\
\hline FDI does not Granger Cause GRP & 1 & $5.276^{* *}$ \\
GRP does not Granger Cause FDI & & \\
\hline \hline [FDI-less-intensive Region] & df & Chi-sq \\
\hline Null Hypothesis & 1 & $7.676 * * *$ (negative) \\
\hline FDI does not Granger Cause GRP & 1 & $7.603 * * *$ \\
\hline GRP does not Granger Cause FDI
\end{tabular}

Note: $* * *, * *$ denote the rejection of null hypothesis at the $99 \%$ and $95 \%$ level of significance. Sources: Author's estimation 
Table 3.3: Variance Decomposition

[Nationwide]

\begin{tabular}{|c|c|c|c|c|}
\hline & \multicolumn{2}{|c|}{ Variance Decomposition of GRP } & \multicolumn{2}{|c|}{ Variance Decomposition of FDI } \\
\hline & FDI & GRP & FDI & GRP \\
\hline 1st Quarter & 2.361 & 97.639 & 100.000 & 0.000 \\
\hline 2nd Quarter & 10.782 & 89.218 & 99.960 & 0.040 \\
\hline 3rd Quarter & 18.259 & 81.741 & 99.856 & 0.144 \\
\hline 4th Quarter & 23.914 & 76.086 & 99.676 & 0.324 \\
\hline 5th Quarter & 28.024 & 71.976 & 99.408 & 0.592 \\
\hline 6th Quarter & 30.998 & 69.002 & 99.042 & 0.958 \\
\hline 7th Quarter & 33.165 & 66.835 & 98.561 & 1.439 \\
\hline 8th Quarter & 34.758 & 65.242 & 97.945 & 2.055 \\
\hline \multicolumn{5}{|c|}{ [FDI-intensive Region] } \\
\hline & \multicolumn{2}{|c|}{ Variance Decomposition of GRP } & \multicolumn{2}{|c|}{ Variance Decomposition of FDI } \\
\hline & FDI & GRP & FDI & GRP \\
\hline 1st Quarter & 4.357 & 95.643 & 100.000 & 0.000 \\
\hline 2nd Quarter & 11.898 & 88.102 & 99.991 & 0.009 \\
\hline 3rd Quarter & 30.285 & 69.715 & 99.965 & 0.035 \\
\hline 4th Quarter & 45.408 & 54.592 & 99.919 & 0.081 \\
\hline 5th Quarter & 55.720 & 44.280 & 99.846 & 0.154 \\
\hline 6th Quarter & 62.602 & 37.398 & 99.740 & 0.260 \\
\hline 7th Quarter & 67.283 & 32.717 & 99.593 & 0.407 \\
\hline 8th Quarter & 70.554 & 29.446 & 99.396 & 0.604 \\
\hline \multicolumn{5}{|c|}{ [FDI-less-intensive Region] } \\
\hline & \multicolumn{2}{|c|}{ "Variance Decomposition of GRP } & \multicolumn{2}{|c|}{ Variance Decomposition of FDI } \\
\hline & FDI & GRP & FDI & GRP \\
\hline 1st Quarter & 4.127 & 95.873 & 100.000 & 0.000 \\
\hline 2nd Quarter & 42.719 & 57.281 & 99.959 & 0.041 \\
\hline 3rd Quarter & 40.406 & 59.594 & 99.944 & 0.056 \\
\hline 4th Quarter & 42.296 & 57.704 & 99.913 & 0.087 \\
\hline 5th Quarter & 42.247 & 57.753 & 99.881 & 0.119 \\
\hline 6th Quarter & 42.624 & 57.376 & 99.840 & 0.160 \\
\hline 7th Quarter & 42.725 & 57.275 & 99.793 & 0.207 \\
\hline 8th Quarter & 42.859 & 57.141 & 99.735 & 0.265 \\
\hline
\end{tabular}

Sources: Author's estimation 
[Nationwide]
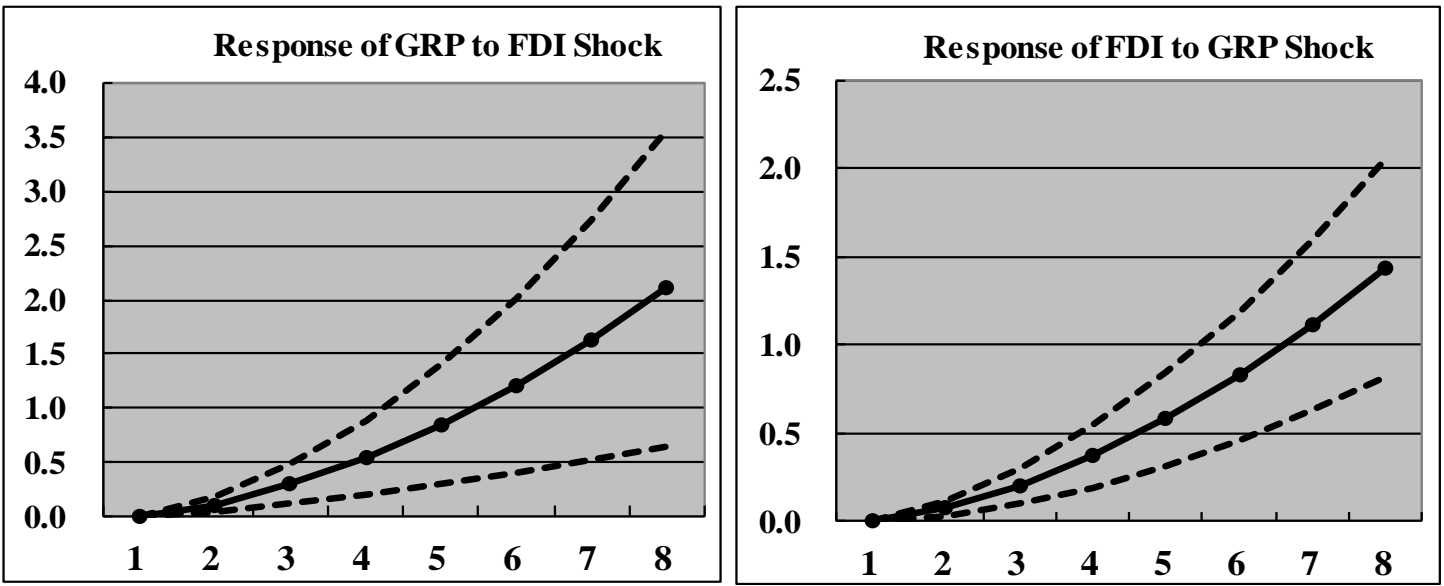

[FDI-intensive Region]
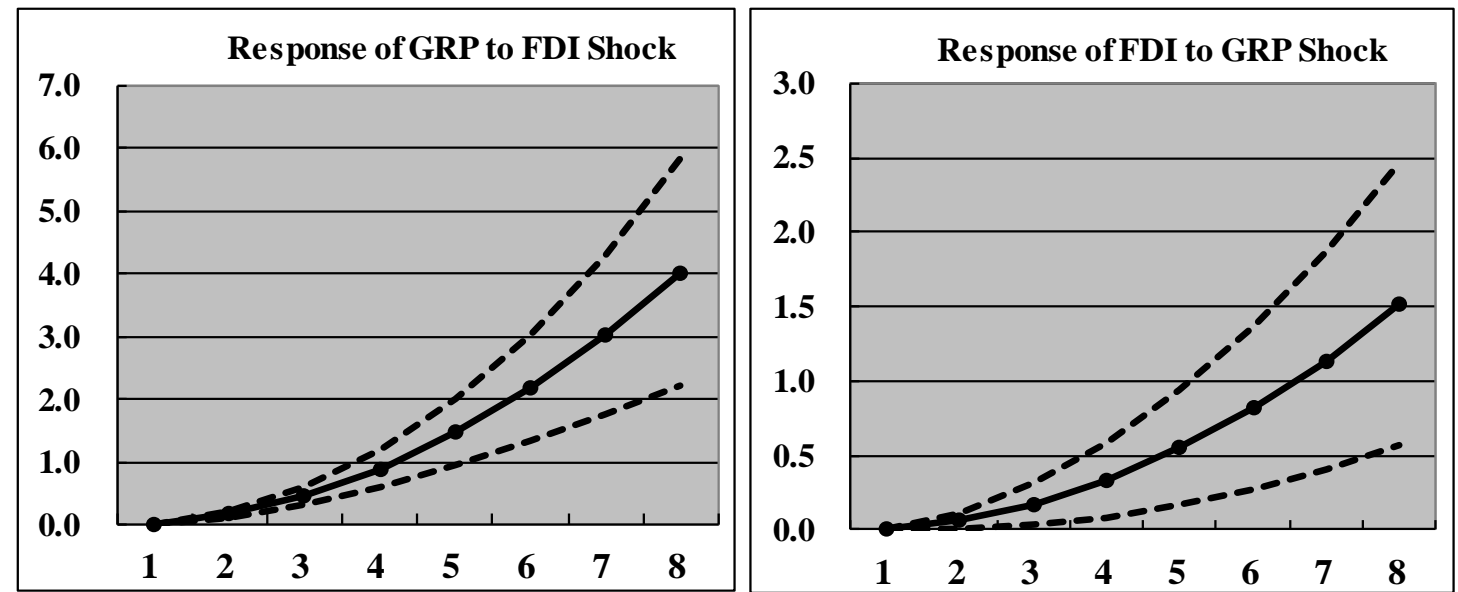

[FDI-less-intensive Region]
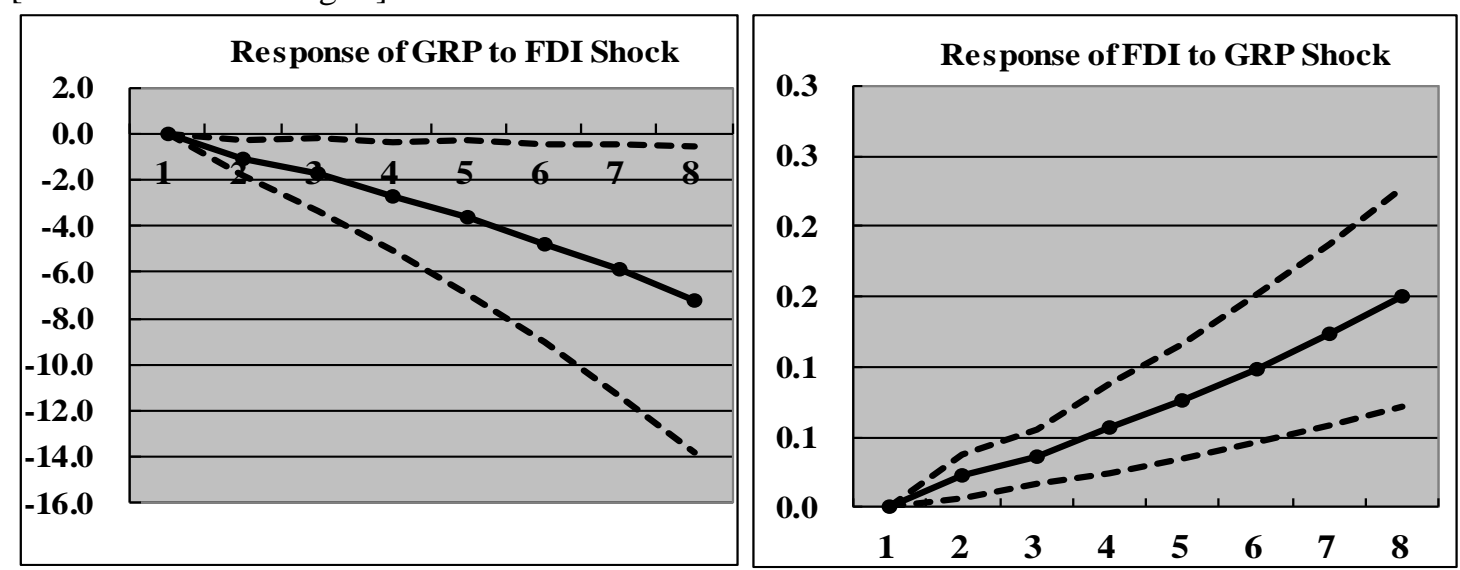

Figure 1: Impulse Responses in Regional Analysis

Note: 1) The shock is defined as one unit innovation.

2) The dotted lines denote a 95 percent error band over 8-year horizons.

Sources: Author's estimation 
Table 4: Sectoral Analysis on Relationship between FDI and DIV

Table 4.1: Estimated PVAR Model

[Total]

\begin{tabular}{ccc}
\hline \hline FDI \& DIV & FDI & DIV \\
\hline \multirow{2}{*}{ FDI-1 } & $0.421 * * *$ & 0.050 \\
& {$[3.653]$} & {$[1.155]$} \\
\hline \multirow{2}{*}{ DIV-1 } & 0.414 & $0.233 *$ \\
& {$[1.249]$} & {$[1.858]$} \\
\hline adj. $\mathrm{R}^{\wedge} 2$ & 0.204 & 0.063 \\
\hline \hline [Excluding Oil \& Gas] & & DIV \\
\hline \hline FDI \& DIV & FDI & $0.157 * *$ \\
FDI-1 & $0.547 * * *$ & {$[2.414]$} \\
\hline \multirow{2}{*}{ DIV-1 } & {$[4.723]$} & 0.086 \\
& 0.385 & {$[0.621]$} \\
\hline adj. $\mathrm{R}^{\wedge} 2$ & {$[1.567]$} & 0.114 \\
\hline \hline
\end{tabular}

Note: $* * *, * * *$ denote the rejection of null hypothesis at the $99 \%, 95 \%$ and $90 \%$ level of significance.

The t-statistic is in parentheses [ ].

Sources: Author's estimation

Table 4.2: Granger Causality Test

[Total]

\begin{tabular}{ccc}
\hline \hline Null Hypothesis & df & Chi-sq \\
\hline FDI does not Granger Cause DIV & 1 & 1.334 \\
DIV does not Granger Cause FDI & 1 & 1.569 \\
\hline \hline [Excluding Oil \& Gas] & & \\
\hline \hline Null Hypothesis & df & Chi-sq \\
\hline FDI does not Granger Cause DIV & 1 & $5.832 * *$ \\
DIV does not Granger Cause FDI & 1 & 2.456 \\
\hline \hline
\end{tabular}

Note: $* *$ denotes the rejection of null hypothesis at the $95 \%$ level of significance.

Sources: Author's estimation 
Table 4.3: Variance Decomposition

[Total]

\begin{tabular}{lcccc}
\hline \hline & \multicolumn{2}{c}{ Variance Decomposition of DIV } & \multicolumn{2}{c}{ Variance Decomposition of FDI } \\
\cline { 2 - 5 } & FDI & DIV & FDIV \\
\hline 1st Quarter & 2.627 & 97.373 & 100.000 & 0.000 \\
2nd Quarter & 5.131 & 94.869 & 98.044 & 1.956 \\
3rd Quarter & 5.960 & 94.040 & 97.328 & 2.672 \\
4th Quarter & 6.184 & 93.816 & 97.130 & 2.870 \\
5th Quarter & 6.242 & 93.758 & 97.078 & 2.922 \\
6th Quarter & 6.256 & 93.744 & 97.065 & 2.935 \\
7th Quarter & 6.260 & 93.740 & 97.062 & 2.938 \\
8th Quarter & 6.261 & 93.739 & 97.061 & 2.939 \\
\hline \hline [Excluding Oil \& Gas] & & & Variance Decomposition of FDI \\
\hline \hline
\end{tabular}

Sources: Author's estimation 
[Total]
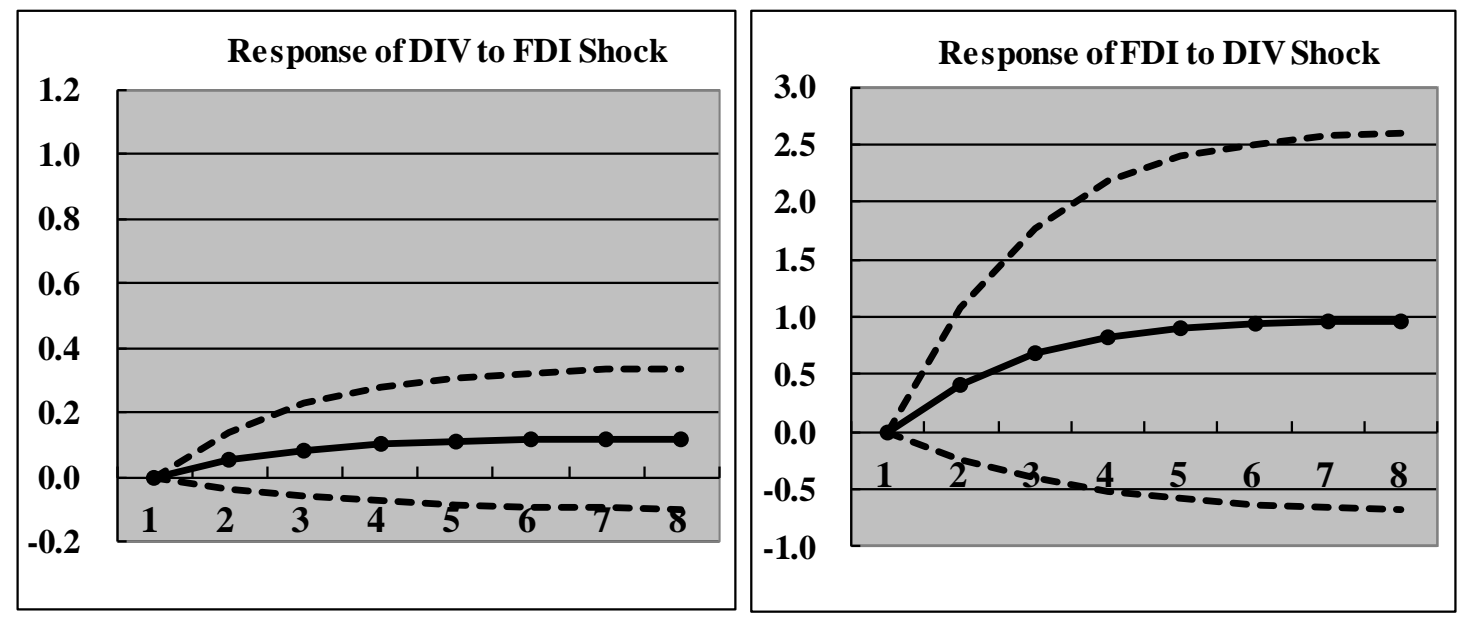

[Excluding Oil \& Gas]
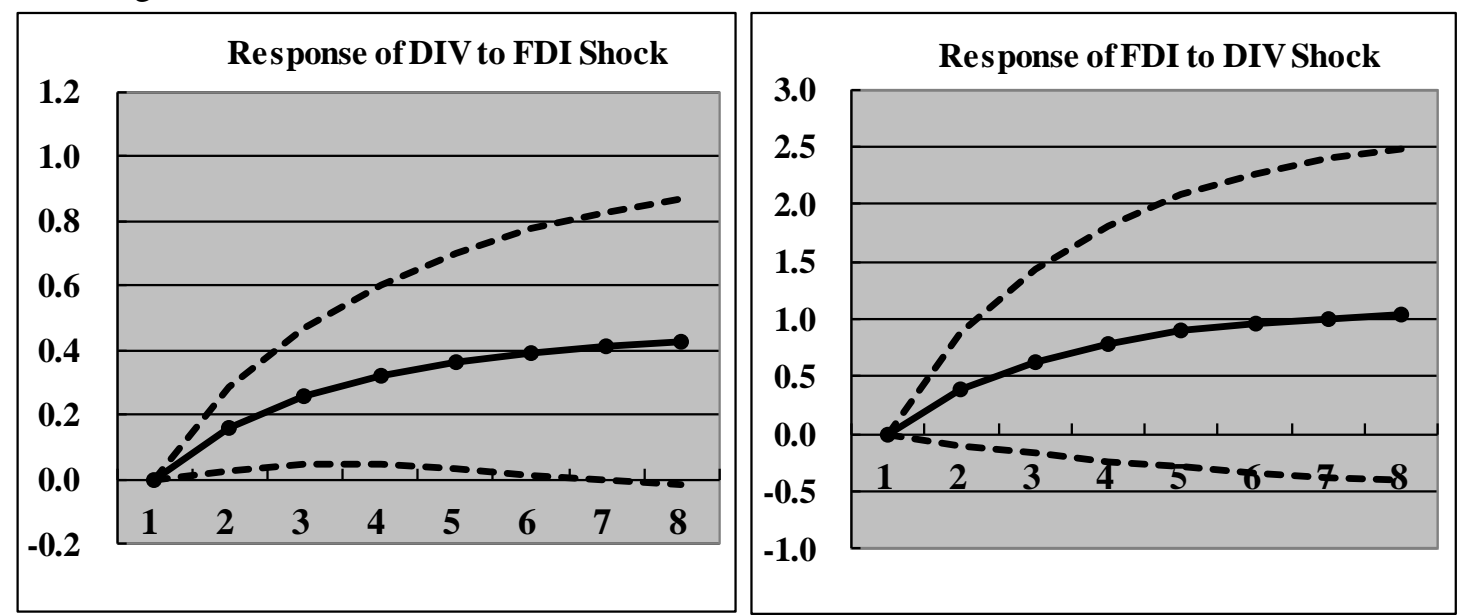

Figure 2: Impulse Responses in Sectoral Analysis

Note: 1) The shock is defined as one unit innovation.

2) The dotted lines denote a 95 percent error band over 8 -year horizons.

Sources: Author's estimation 